\title{
A comparison of lightning human fatalities between Malaysia and United States
}

\begin{abstract}
This study analyzed and compared the lightning related casualties in Malaysia and United States. United States as a developed country is reported with 0.3 deaths per million per year after 1970 comparing to lesser-developed areas such as Malaysia with an annual lightning fatality rate of 6 deaths per million. The comparison and analysis were made based on the rural-urban setting and the six types of activities locations defined as agriculture, indoors, outdoors, recreation, small structures (i.e. vehicle, open-sided shelter, shed) and sports. The results for the both countries were discussed in terms of their differences and similarities.
\end{abstract}

Keyword: Human fatalities; Injuries; Lightning fatalities 